\section{Radiation Exposure in Multi-Slice CT of the Heart}

M. Cohnen'1, L. Poll', C. Püttmann², K. Ewen², U. Mödder ${ }^{1}$

${ }^{1}$ Institute of Diagnostic Radiology, Heinrich-Heine-University, Düsseldorf

${ }^{2}$ Landesanstalt für Arbeitsschutz des Landes NRW, Düsseldorf
Summary. Purpose: To assess radiation exposure of patients undergoing Multi-Row Detector CT (Multi-Slice CT, MSCT) of the heart. Material and Methods: Four different cardiac MSCT protocols with changing slice collimation $(4 \times 1$, and $4 \times 2.5$ $\mathrm{mm})$, and pitch-factor $(1.5,1.8$, and 4$)$ were examined. An anthropomorphic Alderson-Rando phantom was equipped with LiF-thermoluminescent dosimeters at several organ sites, and effective doses were calculated using ICRP-weighting factors. These data were compared to data from standard MSCT of chest and abdomen. Results: Effective dose in different protocols for cardiac MSCT varies from 2.8 to $10.3 \mathrm{mSv}$ (male), and from 3.6 to $12.7 \mathrm{mSv}$ (female). In protocols with thin collimation and low pitch or a combination of several heart examinations, radiation exposure may be comparable to the effective dose of standard MSCT of the chest (male: $11.9 \mathrm{mSv}$, female: $12.9 \mathrm{mSv}$ ) or the abdomen (male: $16.1 \mathrm{mSv}$, female: $15.7 \mathrm{mSv}$ ). Highest organ doses were found for the female breast (up to $46.6 \mathrm{mGy}$ ), and the lungs (up to $36.4 \mathrm{mGy}$ ) with surface doses as high as $54.3 \mathrm{mGy}$. Conclusions: Cardiac MSCT adds significantly to the radiation exposure of patients and can reach the effective dose applied by standard MSCT of chest or abdomen.

Key words: Radiation exposure - Multi-slice CT - Heart - Effective dose - Cardiac CT

Strahlenexposition bei der Mehrschicht-Spiral CT des Herzens. Ziel: Bestimmung der Strahlenexposition von Patienten während einer Mehrschicht-Spiral-CT-(MSCT)Untersuchung des Herzens. Material und Methoden: Vier verschiedene MSCTProtokolle zur Herzuntersuchung mit unterschiedlicher Schichtdicke $(4 \times 1$ bis $4 \times 2.5 \mathrm{~mm})$ und Pitchfaktoren (1,5, 1.8 und 4 ) wurden untersucht. LiF-Thermolumineszenzdosimeter wurden in einem anthropomorphen Alderson-Rando Phantom an verschiedenen Organen positioniert. Die effektive Dosis wurde mit Hilfe der ICRP-Wichtungsfaktoren berechnet. Diese Werte wurden mit den Daten einer Standard-MSCT des Thorax und des Abdomen verglichen. Ergebnisse: Die effektive Dosis einer MSCT des Herzens reicht von 2,8 bis 10,3 mSv (Mann) bzw. 3,6 bis 12,7 mSv (Frau). Besonders bei Protokollen mit dünner Kollimation und niedrigem Pitch oder einer Kombination von Herzuntersuchungen kann es zu einer der Standard-MSCT des Thorax (Mann: 11,9 mSv, Frau: 12,9 mSv) oder des Abdomen (Mann: $16,1 \mathrm{mSv}$, Frau 15,7 mSv) vergleichbaren Strahlenexposition kommen. Bei kardialer MSCT waren die Organdosen der Mamma (bis 46,6 mGy) und der Lunge (bis 36,4 mGy) am höchsten bei einer Oberflächendosis bis 54,3 mGy. Schlussfolgerung: MSCT-Untersuchungen des Herzens führen zu einer signifikanten Strahlenexposition des Patienten, die in der Größenordnung einer Standard-MSCT des Thorax oder Abdomen liegen kann.

Schlüsselwörter: Strahlenexposition - Mehrschicht-Spiral CT Herz - Effektive Dosis - Kardio CT

\section{Introduction}

Imaging of the heart is routinely done using invasive cardangiography, noninvasive echocardiography, or nuclear studies. In the past decade, MR-imaging proved to be reliable in terms of functional assessment of cardiac function [1]. Magnetic resonance angiography of coronary arteries with limited spatial resolution yet has still restricted diagnostic value $[2,3]$. Electron beam tomography as non-invasive technique with high temporal and spatial resolution requires a dedicated specialized hardware and may lead to relatively high radiation doses $[4,5]$.

The introduction of Multi-Row Detector CT (Multi-Slice CT, MSCT) into clinical routine has opened a new field to radiological diagnostics [6]. Coronary arteries can be depicted with high spatial resolution $[7,8]$. MSCT with thin slice collimation allows a full scan of the heart within one breath-hold to evaluate cardiac calcification [9]. However, first data hint at a relatively high radiation exposure during MSCT of the heart $[10,11]$. Therefore, this study was performed to investigate the radiation dose applied during cardiac MSCT in comparison to routine CT-scanning of the chest or the abdomen.

\section{Materials and Methods}

Dose measurements were performed at a Multi-Row detector CT scanner (MSCT) “Somatom Plus 4 Volume Zoom” (Siemens, Erlangen). Technical parameters of the different CT-examinations may be taken in detail from Table $\mathbf{1}$. 


\begin{tabular}{lcccccc}
\hline & Abdomen CT & Chest CT & Heart 1 & Heart 2 & Heart 3 & Heart 4 \\
\hline effective mAs & 165 & 120 & 120 & 133 & 330 & 400 \\
KV & 120 & 140 & 120 & 140 & 120 & 120 \\
Slice [mm] & 5 & 2.5 & 2.5 & 2.5 & 1 & 1 \\
Feed [mm] & 25 & 15 & 10 & 3.8 & 1.8 & 1.5 \\
Pitch & 5 & 6 & 4 & 1.52 & 1.8 & 1.5 \\
Duration [sec] & 10.1 & 12.2 & $0.36 \times 13$ & 19.9 & 38 & 42.6 \\
Length [mm] & 467 & 333 & 127.5 & 130 & 130 & 130 \\
CTDI $_{\text {w,eff [mGy] }}$ & 14.2 & 16.4 & 15.6 & 18.4 & 37.6 & 45.6 \\
\hline
\end{tabular}

Table 1: Technical parameters of CT examinations ("Heart 1": prospectively ECGtriggered sequential; "Heart 2": Calcium Scoring Spiral; "Heart 3": Coronary Spiral Fast; "Heart 4": Coronary Spiral Standard. "Heart 2 - 4" with retrospective ECG-gating)
The MSCT used in this study allows a slice collimation varying from 0.5 to $5 \mathrm{~mm}$. For chest CT, a slice collimation of $2.5 \mathrm{~mm}$ and a pitch factor of 6 were chosen with $15 \mathrm{~mm}$ table feed per rotation according to the routine scanning procedure. For Abdomen CT, a $5 \mathrm{~mm}$ collimation was set with a pitch of 5 .

For the cardiac examinations, the software package "Heart View" (software version "Somaris/5 VA 20 A", Siemens, Erlangen) was available. Different settings were applied in cardiac imaging: prospectively ECG-triggered sequential scans are obtained using $2.5 \mathrm{~mm}$ slice width, and a table feed of $10 \mathrm{~mm}$ (protocol "Heart 1"). Calcium scoring is performed using a $2.5 \mathrm{~mm}$ collimation with a pitch of 1.52 , corresponding to a table feed of $3.8 \mathrm{~mm}$ ("Heart 2"). Coronary arteries or bypasses can be depicted with a $1 \mathrm{~mm}$ slice collimation. In order to scan the entire heart in a fast mode a table feed of $1.8 \mathrm{~mm}$ (Pitch 1.8 ) is applied ("Heart 3"). For high resolution, a table feed of 1.5 (Pitch 1.5) is chosen ("Heart 4"). As all the latter protocols ("Heart $2-4$ ") are usually performed by use of a retrospective ECG-gating and the software does not allow a start of spiral scanning without detection of an ECG-signal, a healthy volunteer was connected to the electrodes and placed outside the CT-scanning suite. Image acquisition was achieved with a regular heart rate of $70-80$ beats per minute.

The implemented standard CT software displays the effective weighted CTDI $\left(\mathrm{CTDI}_{\mathrm{w} \text {,eff }}\right)$ computed and calculated from the examination settings. Using this $\mathrm{CTDI}_{\mathrm{w}, \text { eff }}$ we calculated the effective dose according to the following equation:

$\mathrm{E}[\mathrm{mSv}]=\mathrm{CTDI}_{\mathrm{w}, \mathrm{eff}} \times(\mathrm{n} \times \mathrm{TV}) \times 1 / \mathrm{P}_{\mathrm{B}} \times \mathrm{f}_{\text {mean }} \times \mathrm{k}_{\mathrm{CT}}$.

$\mathrm{CTDI}_{\mathrm{w}, \mathrm{eff}}$ : effective weighted CTDI [mGy]; ( $\mathrm{x}$ TV): scan length $[\mathrm{cm}] ; \mathrm{P}_{\mathrm{B}}$ : conversion of $\mathrm{CTDI}_{\mathrm{w}, \mathrm{eff}}$ to $\mathrm{CTDI}_{\text {Air }}(=0.49) ; \mathrm{f}_{\text {mean }}$ : mean of organ conversion factors $[\mathrm{mSv} /(\mathrm{mGy} \times \mathrm{cm})]$; $\mathrm{kCT}$ : scanner specific correction factor dependent on $\mathrm{kV} \mathrm{[12].}$

An Alderson-Rando anthropomorphic phantom was used to assess radiation exposure. It was equipped with at least $30 \mathrm{LiF}$ Thermoluminescent dosimeters, which were analyzed using a Glowcurve analyzer Harshaw filtrol 2000D (Harshaw, Cleveland). TLD were read out within 12 hours after exposure so that fading was nearly avoided. In order to transfer the measured electrical charge $[\mathrm{nC}]$ into dose values [mGy], data had to be multiplied with a correction factor of $0.82 \mathrm{mGy} / \mathrm{nC}$ as the CT scanner uses a beam filter of $1.4 \mathrm{~mm}$ aluminium and $1.2 \mathrm{~mm}$ Titanium. In order to obtain reliable results, every examination was repeated four times and the resulting data were divided by four. Positions of TLD were chosen such that data from all organs within the primary beam were gained as well as from very radiation sensitive organs like the ovaries or testes. One TLD was positioned per location with at least two TLD forming the basis for organ doses. Data from TLD directly positioned within an organ (thyroid, gonads) were directly used to define the organ dose after addition of the measured values and division by the number of TLD. In larger organs (lungs, liver, esophagus), an organ dose was estimated as mean of at least three TLD positioned in the region of this organ. Dose calculation of the bone marrow was achieved by adding data from TLD in several locations (clavicle, scapula, sternum, two ribs, thoracic and lumbar vertebrae, and pelvis) and multiplying with the relative red marrow distribution in the different bones. The surface dose was calculated from three TLD positioned on the surface of the phantom (two on the front, one on the back) within the area of the primary beam and equated with the skin dose. Although skin dose should be measured $0.7 \mathrm{~mm}$ under the surface, a detectable difference to surface note is not expected. As it is difficult to define and to reproduce the correct percentage of how much surface or skin might have been exposed, we calculated the effective dose from the data measured in the primary beam taking into account that the effective dose might be slightly lower. However, as the weighting factor for skin is 0.01 the influence will only be marginal. Effective dose results from addition of the single organ doses after multiplication with the weighting factor (International Committee on Radiation Protection, ICRP 60). Separate calculations for male and female patients were done as different organs and therefore organ doses are relevant.

\section{Results}

For standard MSCT of the chest, organs within the range of the primary beam revealed radiation doses from $15.0 \mathrm{mGy}$ (liver) to 27.9 mGy (esophagus) (Table 2). Organs outside this area including the gonads did not show radiation doses higher than $0.5 \mathrm{mGy}$. The effective dose applied by MSCT of the chest summed up to $12.9 \mathrm{mSv}$ (female), and $11.9 \mathrm{mSv}$ (male) Table 3 ). The dose distribution within the area of the primary beam was quite uniform including the surface skin dose (28.3 $\mathrm{mGy}$ ).

In standard MSCT of the abdomen, doses of organs within the primary beam were within a range of $19.0 \mathrm{mGy}$ (bladder) and $24.9 \mathrm{mGy}$ (stomach). The surface dose in the area of the primary beam was $26.2 \mathrm{mGy}$. Table 2 demonstrates the distribution of relatively uniform organ doses throughout the abdomen. The effective dose added up to $15.7 \mathrm{mSv}$ (female), and $16.1 \mathrm{mSv}$ (male), respectively (Table $\mathbf{3}$ ). 


\begin{tabular}{llccccc}
\hline [mGy] & Abdomen CT & Chest CT & Heart 1 & Heart 2 & Heart 3 & Heart 4 \\
\hline Thyroid Gland & 0 & 23.8 & 0.6 & 0 & 2 & 2.1 \\
Esophagus & 3.8 & 27.9 & 4.4 & 8.2 & 14.6 & 18.0 \\
Female Breast & 2.7 & 19.9 & 14.9 & 20.9 & 39.7 & 46.6 \\
Lungs & 8.3 & 25.4 & 9.1 & 18.6 & 32.2 & 36.4 \\
Stomach & 24.9 & 26.0 & 4.3 & 7.5 & 13.3 & 14.1 \\
Liver & 23.5 & 15.0 & 3.5 & 5.8 & 10.6 & 11.5 \\
Colon & 23.6 & 1.4 & 0 & 0 & 0 & 0 \\
Bladder & 19.0 & 0 & 0 & 0 & 0 & 0 \\
Gonads (Ovary) & 20.5 & 0.4 & 0.5 & 0.2 & 0.4 & 0.7 \\
Gonads (Testes) & 23.0 & 0.3 & 0.2 & 0.2 & 0.3 & 0.4 \\
Skin & 26.2 & 28.3 & 15.3 & 22.5 & 54.3 & 50.1 \\
Bone Marrow & 11.5 & 8.4 & 2.3 & 4.3 & 7.7 & 9.1 \\
\hline
\end{tabular}

Table 2: Organ doses [mGy] measured by LiF-TLD for different CT examinations ("Heart 1": prospectively ECG-triggered sequential; "Heart 2": Calcium Scoring Spiral; "Heart 3": Coronary Spiral Fast; "Heart 4": Coronary Spiral Standard. "Heart 2 - 4" with retrospective ECG-gating)

\begin{tabular}{lcccccc}
\hline [mSv] & Abdomen CT & Chest CT & Heart 1 & Heart 2 & Heart 3 & Heart 4 \\
\hline $\begin{array}{l}\text { effective dose } \\
\text { (female, meas.) }\end{array}$ & 15.7 & 12.9 & 3.6 & 6.2 & 11.2 & 12.7 \\
$\begin{array}{l}\text { effective dose } \\
\text { (female, calc.) }\end{array}$ & 13.5 & 10.8 & 3.7 & 4.7 & 9.0 & 11.0 \\
$\begin{array}{l}\text { effective dose } \\
\text { (male, meas.) }\end{array}$ & 16.1 & 11.9 & 2.8 & 5.1 & 9.2 & 10.3 \\
$\begin{array}{l}\text { effective dose } \\
\text { (male, calc.) }\end{array}$ & 9.7 & 8.2 & 2.8 & 3.6 & 6.8 & 8.3 \\
\hline
\end{tabular}

Table 3: Effective doses both measured by LiF-TLD ("meas.") as well as calculated by use of CTDI ${ }_{w}$ ("calc.", see text). ("Heart 1": prospectively ECG-triggered sequential; "Heart 2": Calcium Scoring Spiral; "Heart 3": Coronary Spiral Fast; "Heart 4": Coronary Spiral Standard. "Heart 2 - 4" with retrospective ECG-gating). Effective doses are calculated using conversion factors (ICRP 60).

For the MSCT-examination of the heart, different protocols were tested. The least effective dose was seen in the sequential technique with prospective ECG-triggering ("Heart 1"). Highest exposure was noted at the site of the the female breast with a local organ dose of $14.9 \mathrm{mGy}$. After multiplication with the weighting factor, an effective dose of $3.6 \mathrm{mSv}$ (female), and 2.8 $\mathrm{mSv}$ (male) was calculated. The calcium scoring protocol ("Heart 2") with a spiral scan using $2.5 \mathrm{~mm}$ collimation revealed a radiation exposure nearly twice as high: $6.2 \mathrm{mSv}$ (female), and $5.1 \mathrm{mSv}$ (male). Radiation dose for the female breast was $20.9 \mathrm{mGy}$, and for the lungs $18.6 \mathrm{mGy}$. Surface dose of the skin in both modalities was 15 and $22 \mathrm{mGy}$, respectively.

In high resolution MSCT of the heart a $1 \mathrm{~mm}$ collimation is used to delineate the coronary arteries. Both in the fast ("Heart 3") and the standard mode ("Heart 4") an effective dose of up to $12.7 \mathrm{mSv}$ for women, and $10.3 \mathrm{mSv}$ for men is reached. Highest organ doses were found again for the female breast (up to 46.6 $\mathrm{mGy}$ ), and the lungs (up to $36.4 \mathrm{mGy}$ ), with a surface skin dose exceeding $50 \mathrm{mGy}$. Gonadal doses for all the MSCT of thoracic regions were not higher than $0.7 \mathrm{mGy}$. Detailed results both for all organ doses as well as the effective dose are displayed in Tables $\mathbf{2}$, and $\mathbf{3}$ as well as. These protocols show a relatively high dose within the primary beam with a rapid decline to organs and regions in the direct vicinity.

The calculation of the effective dose by use of the CTDI ${ }_{w, e f f}$ showed results mainly close to the actual measured data. However, in some cases an overestimation of up to $9 \%$ (protocol "Heart 1", female dose) was seen (Table 3). Significant underestimation of radiation dose occurred in routine abdomen and chest CT (up to $39 \%$ ).

\section{Discussion}

Multi-slice CT of the heart is a new and promising imaging modality with the potential to allow risk stratification of patients for coronary events by prospective calcium scoring, to delineate coronary arteries and bypasses with high spatial resolution as well as to analyze functional parameters like ejection fraction $[7-9,13]$. However, a disadvantage in comparison to magnetic resonance imaging (MRI) is the use of ionizing radiation. First data hint at a significant radiation exposure in MSCT with dose values known from electron beam tomography $[10,11]$.

The data presented in this study show that with a collimation of $2.5 \mathrm{~mm}$ effective doses of around $3 \mathrm{mSv}$ for multi-slice sequential scanning, and $5 \mathrm{mSv}$ for multi-slice spiral scanning with retrospective ECG-gating are realistic. In MSCT of the heart in order to delineate coronary arteries or bypasses noninvasively, a thinner collimation is mandatory. In consequence, a higher mAs-product is needed to maintain image quality as there is a direct relationship between image noise and photon flux [14]. Thus, protocols "Heart 3" and "Heart 4" are performed with $330 \mathrm{mAs}$, and $400 \mathrm{mAs}$, respectively. In these protocols, an effective dose of 9.2 to $12.7 \mathrm{mSv}$ was be found. Another reason for this relatively high effective dose is the significant slice overlap of $55 \%$, and $62,5 \%$, respectively, resulting from a pitch of 1.8 or 1.5 in a 4-detector-row scanning system ("volume pitch"; Table 1). This accounts for the equation table feed per slice collimation. In view of four detector rows, this converts to a pitch of 0.45 , and 0.375 (table feed per slice collimation times four). Main contributions to the effective dose result from the organ doses of the lungs, the female breast and the stomach, all situated within the primary beam. Other organs including the gonads add only marginally. In case of a combined study with 
calcium scoring and CT coronary angiography performed in the same patient, effective doses need to be added so that a total dose of up to $13 \mathrm{mSv}$ (male) or $16 \mathrm{mSv}$ (female) may result.

The mAs-product is set automatically and can be varied within limits. Keeping to the same $\mathrm{kVp}$, however, different scan protocols can easily be transferred by multiplying or dividing data from this study after normalization to $100 \mathrm{mAs}$. Protocol "Heart 4", for example, being performed with $300 \mathrm{mAs}$ instead of $400 \mathrm{mAs}$ leads then to an effective dose of 7.7 to $9.5 \mathrm{mSv}$. How far the mAs-product may be reduced in order to allow low dose examinations without negative results in terms of image quality needs still to be established. First efforts in terms of dose reduction strategies have shown the perspective to halve the effective dose of MSCT of the heart [11].

Previous data showed that effective doses of up to $8 \mathrm{mSv}$ may be expected when detailed cardiac examinations are performed by electron beam tomography (EBT) with an estimation of $2.5 \mathrm{mSv}$ for calcium Scoring in combination with EBT-coronary angiography [10]. These values were found in protocols with $3 \mathrm{~mm}$ slice collimation and a table feed of $3 \mathrm{~mm}$, and $2 \mathrm{~mm}$, respectively, as well as in dynamic $7 \mathrm{~mm}$ thick slices without table feed [10]. Therefore, spatial resolution may not have been as high as in the settings chosen in the present work. Although first data indicate that MSCT of the heart may be more accurate than EBT, the impact of slice thickness on diagnostic accuracy needs to be defined by further studies.

Routine coronary angiography leads to an effective dose of 3 to $4 \mathrm{mSv}[10,15]$. This is true for standard diagnostic procedures performed by experienced personnel. In case of an intervention, higher doses may be expected. In the setting of non-invasive CT coronary angiography, radiation exposure may be nearly double as high.

In comparison, standard MSCT of the chest and the abdomen were shown to apply an effective dose of around 12 to $16 \mathrm{mSv}$ using the "Somatom Plus 4 Volume Zoom". This tends to be higher than effective doses have been reported in previous studies with single slice CT although we used lower mAsproduct as preset $[10,16,17]$. Main reason may be the thinner slice collimation with $2.5 \mathrm{~mm}$ for the chest CT, and $5 \mathrm{~mm}$ for the abdomen CT as compared to 8 or $10 \mathrm{~mm}$ as generally used in single slice scanners. Although it has been termed "standard" chest $\mathrm{CT}$, a routine scan procedure may be performed with a $5 \mathrm{~mm}$ collimation with a potentially lower effective dose as tube current may be lowered further with image noise remaining constant. In addition, MSCT may have a reduced dose efficiency compared to single-slice CT, as a dead space exists between the detector rows due to mechanical dividers which absorb x-rays without adding to signal output. Furthermore, a relatively large area before and after the actual scan volume needs to be covered to gain sufficient data to calculate and reconstruct the first and last slices. This area might be larger in MSCT compared to single-slice CT, so that for example the male gonads are exposed within the primary beam when scanning the abdomen. This contribution to effective dose may be reduced effectively by applying gonadal shields.

When performing cardiac MSCT scan coverage is limited to a small region of the thorax. By reason of a high mAs-product and low pitch factors a relatively high localized radiation dose is applied with abrupt decrease outside the area of the primary beam. On the contrary, MSCT of the chest or abdomen lead to a more uniform dose distribution. However, effective dose of cardiac MSCT may be in the same range as routine CT protocols when organs with high weighting factors are exposed.

It is well known that mathematical estimations of effective doses for CT protocols may underestimate the radiation exposure up to $30 \%$ [10]. The present study underlines that a calculation of the effective dose based on the $\mathrm{CTDI}_{\mathrm{w} \text {,eff }}$ computed by the implemented software of the scanner does not improve these results. In the present paper, a slight overestimation of up to $5 \%$ as well as an underestimation of effective doses of up to $40 \%$ was noted. Significant underestimation occurred in the routine chest and abdomen CT protocols perhaps resulting from an under-representation of the gonadal dose in the calculation. As overestimation was observed in particular for the sequential cardiac protocol, the inhomogeneous dose distribution in cardiac MSCT may probably not be reflected in the static mathematical formula. It should be acknowledged, however, that accuracy ranges of LiF-TLD lie between 5 and $10 \%$. In order to improve the reliability of measurements we used at least two TLD per location and performed all CT-protocols four times.

In conclusion, MSCT of the heart may lead to effective doses comparable to those reached by standard examinations of the chest or abdomen. However, radiation exposure for calcium scoring protocols are within the range of standard coronary angiography. Therefore, these protocols seem feasible in view of non-invasive screening examinations. Further studies need to be done on the combined aspect of dose reduction and image quality. In cases of visualization of high contrast structures a significant reduction in radiation dose may be achieved. However, CT-coronary angiography or cardiac function analysis may require higher scan parameters and therefore effective doses within the range of standard CT of the chest or the abdomen may be applied. In how far this radiation exposure may be justified by the diagnostic impact of cardiac MSCT remains to be clarified in future studies. The data presented here may serve as basis for further discussion and research.

\section{Acknowledgements}

Dose measurements using the Alderson-Rando-Phantom form part of the doctoral thesis of C. Püttmann.

We are indebted to Dr. H.D. Nagel (Philips Medical Systems, Hamburg, Germany) for valuable discussion.

\section{References}

${ }^{1}$ Koch JA, Poll LW, Godehardt E, Korbmacher B, Mödder U. Right and left ventricular volume measurements in an animal heart model in vitro: first experiences with cardiac MRI at $1.0 \mathrm{~T}$. Eur Radiol 2000; 10: $455-458$

${ }^{2}$ Kessler W, Laub G, Achenbach S, Ropers D, Moshage W, Daniel W. Coronary arteries: MR angiography with fast contrast-enhanced three-dimensional breath-hold imaging-initial experience. Radiology 1999; 210: 566-572

${ }^{3}$ von Smekal A, Knez A, Seelos K, Haberl R, Spiegl F, Reichart B, Steinbeck G, Reiser M. Vergleich der ultraschnellen Computertomographie, der Magnetresonanzangiographie und der selekti- 
ven Angiographie zum Nachweis der Offenheit koronarer Bypasses. Fortschr Röntgenstr 1997; 166: 185-191

${ }^{4}$ Becker A, Becker C, Knez A, Haberl R, Bruning R, Reiser M, Steinbeck G. Funktionsuntersuchungen des Herzens mit der Elektronenstrahltomographie. Radiologe. 1998; 38: 1021 - 1028

${ }^{5}$ Weisser G, Lehmann KJ, Scheck R, Coppenrath E, Fehrentz D, Georgi M. Abbildungseigenschaften der Elektronenstrahl-CT. Radiologe 1998; 38: 993 -998

${ }^{6}$ Ohnesorge B, Flohr T, Becker C, Knez A, Kopp AF, Fukuda K, Reiser MF. Herzbildgebung mit schneller, retrospektiv EKG-synchronisierter Mehrschichtspiral-CT. Radiologe 2000; 40: 111-117

${ }^{7}$ Kopp A, Ohnesorge B, Flohr T, Georg C, Schröder S, Kuttner A, Martensen J, Claussen C. Multidetector CT des Herzens: Erste Klinische Anwendung einer retrospektiv EKG-gesteuerten Spirale mit optimierter zeitlicher und örtlicher Auflösung zur Darstellung der Herzkranzgefäße. Fortschr Röntgenstr 2000; 172: 429-435

${ }^{8}$ Knez A, Becker C, Ohnesorge B, Haberl R, Reiser M, Steinbeck G. Noninvasive detection of coronary artery stenosis by multislice helical computed tomography. Circulation 2000; 101: E221 -E222

${ }^{9}$ Fischbach R, Heindel W. Koronarkalkdetektion und -quantifizierung: Eine Standortbestimmung. Fortschr Röntgenstr 2000; 172: 407-414

${ }^{10}$ Becker C, Schätzl M, Feist H, Bäuml A, Schoepf U, Michalski G, Lechel U, Hengge M, Brüning R, Reiser M. Abschätzung der effektiven Dosis für Routineprotokolle beim konventionellen CT, Elektronenstrahl-CT und bei der Koronarangiographie. Fortschr Röntgenstr 1999; 170: 99-104

11 Ohnesorge B, Flohr T, Becker C, Kopp A, Knez A, Reiser M. Dose Evaluation and Dose Reduction Strategies for ECG-Gated MultiSlice Spiral CT of the heart. Radiology 2000; 217 (P): 487

12 Nagel HD (Hrsg.), Galanski M, Hidajat N, Maier W, Schmidt T. Strahlenexposition in der Computertomographie - Grundlagen, Einflussfaktoren, Dosisermittlung, Optimierung, Zahlenwerte, Begriffe. Frankfurt. ZWEI Fachverband Elektromedizinische Technik 1999

${ }^{13}$ Bahner M, Albers J, Boese J, Schroeder A, Hagl S, Vahl C, van Kaick G. EKG-Gating von Spiral-CT-Datensätzen des Herzens: Eine neue Methode zur Bestimmung der Ejektionsfraktion. Fortschr Röntgenstr 2000; 172: S 487

${ }^{14}$ Wang G, Vannier MW. Low-contrast resolution in volumetric Xray-CT - analytical comparison between conventional and spiral CT. Med.Phys. 1997; 24: 373-376

${ }^{15}$ Leung KC, Martin CJ. Effective doses for coronary angiography. Br J Radiol 1996; 69: 426-431

${ }^{16}$ Scheck R, Coppenrath E, Kellner M, Lehmann K, Mayer M, Rock C, Rieger J, Rothmeier L, Schweden F, Sokiranski R, Bauml A, Hahn K. Dosismessung für Einzelschicht- und Spiralmodus bei 8 Spiral-CTScannern der neuesten Generation. Fortschr Röntgenstr 1998; 168: $562-566$

${ }^{17}$ van Unnik J, Broerse JJ, Geleijns J, Jansen JT, Zoetelief J, Zweers D. Survey of CT techniques and absorbed dose in various Dutch hospitals. Br.J.Radiol. 1997; 70: 367-371
Dr. med. M. Cohnen

Inst. f. Diagn. Radiologie

Heinrich-Heine-Universität, MNR-Klinik

Moorenstr.5

40225 Düsseldorf

Tel. $+49211-81-17752$

Fax +49211-81- 16145

E-mail: cohnen@ uni-duesseldorf.de 